\title{
Implementation of the circular supply chain management in the pharmaceutical industry
}

\author{
Feroz Khan ${ }^{1} \cdot$ Yousaf $^{A^{2}{ }^{2}}{ }^{\text {D }}$
}

Received: 15 February 2021 / Accepted: 25 November 2021 / Published online: 10 January 2022 (c) The Author(s), under exclusive licence to Springer Nature B.V. 2021

\begin{abstract}
The ever-increasing levels of pollution and waste creation have subjected industries around the world to incorporate the concept of circular economy (CE) in their supply chains. The amalgamation of the $\mathrm{CE}$ approach along with supply chain management is called circular supply chain management (CSCM). Among other industries, the pharmaceutical industry is also involved in damaging the ecosystem. Hence, an effective framework for the adoption of CSCM in a particular industry is very essential. Therefore, this paper aims to devise a model that will help the pharmaceutical industries to adopt CSCM in their organizations. For this purpose, the study in the first phase identifies ten barriers that are working as an impediment in the adoption of the CSCM approach. To counter those barriers, the study in the second phase identifies a set of twelve enablers. To analyse the barriers and enablers, the study uses a new hybrid methodology. For allocating weights and prioritizing the barriers, the fuzzy multi-criteria decision-making (MCDM) technique, i.e. fuzzy full consistency method (F-FUCOM) is used, whereas the total quality management tool, i.e. fuzzy quality function deployment (FQFD) is used to rank the enablers. The results from F-FUCOM suggest "lack of financial resources and funding", "market challenges", and "lack of coordination and collaboration among the entire supply chain network" to be the top-most barriers, respectively, whereas the results achieved from the FQFD suggest "industrial symbiosis", "Reverse Logistic (RL) infrastructure", and "block chain technology" to be the top-ranked enablers, respectively. The provision of a facilitating framework for the adoption of CSCM in the pharmaceutical industry and the newly developed hybrid methodology are both novelties of this study.
\end{abstract}

Keywords Circular economy · Circular supply chain management · Pharmaceutical · Fuzzy logic $\cdot$ Multi-criteria decision making $\cdot$ Quality function deployment

Yousaf Ali

yousafkhan@giki.edu.pk

Feroz Khan

gem1970@giki.edu.pk

1 MS in Engineering Management, School of Management Sciences, Ghulam Ishaq Khan Institute of Engineering Sciences \& Technology, Topi, Swabi, KPK, Pakistan

2 School of Management Sciences, Ghulam Ishaq Khan Institute of Engineering Sciences \& Technology, Topi, Swabi, KPK, Pakistan 


\section{Introduction}

With the growing population and increase in the rate of industrialization, the world in 2016 generated 2.01 billion tons of solid waste. The preceding number is expected to rise to 3.40 billion tons of waste in 2050 if the world does not shift to more sustainable practices (The World Bank, 2019). Traditional world economies run on the concept of the linear economy, which works on the principle of make, use, and dispose of principle, which does not only create waste but it is also not a sustainable form of economy. To become more sustainable, the industries around are shifting towards the concepts of CE. The CE model works on the principle of reduce, reuse, and recycle policy. The new model does not create waste and helps in the continual use of resources. More recently, the industries are shifting towards the incorporation of the CE principle into their supply chain operations for maximum sustainability. To achieve all three metrics of sustainability, the United Nations have devised the sustainable development goals (SDGs). The concept of CE meets several goals of SDGs but the strongest relationship exists with that of SDG 12, i.e. "responsible consumption and production" (Schroeder et al., 2019).

Developed nations around the world especially the European Union (EU) have set targets to adopt the CE model. For this, the European Commission has come up with legislative and non-legislative measures to achieve its targets. The aim is to reduce the consumption footprint and ensure the continued use of products in the EU economy. According to a survey, the adoption of the CE model in the EU economy has the potential to increase its GDP by $0.5 \%$ long with the creation of a market of 700,000 (European Commission, 2018). Emerging economies like China have also started to enact the principles of CE in their supply chains. They intend to achieve this goal through the development of industrial ecology (Mathews et al., 2011). Developing countries, on the other hand, are also adopting the new model because of the economic benefits associated with it (Ngan et al., 2019). The concept of CSCM is a novel approach that is being adopted by various industries around the world. These industries include packaging (Batista et al., 2019), automobile (Agyemang, 2019), leather (Moktadir et al., 2020), food (Sharma et al., 2019), and the textile industry (Jia et al., 2020). Manufacturing and process industries are at the forefront in adopting the CSCM in their organizations; however, the process industry, i.e. pharmaceutical industry has got little attention in this regard (Lahane et al., 2020).

The pharmaceutical is one of the biggest industries in the world that has significantly grown in the past two decades. In 2019 alone, the industry made a business of 1.25 trillion USD worldwide ${ }^{1}$. According to a forecast, the preceding number is expected to rise to 1.59 billion USD in 2024 (Statista, 2020). Due to the huge consumption of medicines worldwide, a considerable amount of waste is generated by the industry. According to the World Health Organization (WHO), pharmaceutical waste consists of all the unwanted pharmaceuticals that include unused, expired, spilled, contaminated pharmaceutical products, vaccines, medicines, and sera. These types of waste are not required and should be disposed of properly (WHO, 1999) $)^{2}$. Essentially out of all the pharmaceutical waste, $85 \%$ of it is non-toxic, whereas the rest $15 \%$ is toxic (WHO, 2018). The disposal of this waste requires the right waste management techniques (Bungau et al., 2018). As the industry majorly contributes to society's health, the burden and responsibility of adopting sustainable practices

\footnotetext{
1 https://www.statista.com/topics/1764/global-pharmaceutical-industry/.

${ }^{2}$ https://www.veolia.com/en/newsroom/thematic-reports/boosting-performances-pharmaceutical-industry.
} 
fall the most on such industries. Therefore, these companies are willing to invest in ecodriven technologies and practices. The inclination towards being sustainable benefits both the companies and the communities at large ${ }^{3}$.

Sustainable pharmaceutical manufacturing has been endorsed by the European Federal Pharmaceutical Industries Association in the 2016 white paper (EFPIA, 2016). The current sustainability model in the pharmaceutical industry is mainly focused on waste mitigation, process mass intensity, life cycle assessment, and green chemistry models. Through these models, the pharmaceutical industry has reduced waste generation, but the overconsumption of resources due to reduced resource efficiency is still a problem (EPA, 2019). The current sustainability model in pharmaceutical manufacturing is not adequate and needs the incorporation of CE across its entire supply chain network. The supply chain operations in the pharmaceutical industry include the sourcing of raw materials, followed by manufacturing, distribution, dispensing logistics, and finally sourcing out the medicines to the pharmacies (Uthayakumar \& Priyan, 2013). The particular industry generates waste that is detrimental to human health and is difficult to handle at the same time. Therefore, the industry needs a supporting framework that could help the industry to minimize its waste in the best possible manner across its supply chain network. Thus, this paper aims to provide a facilitating framework for the pharmaceutical industry to adopt the CSCM approach. The incorporation of CSCM in any organization comes with certain barriers that need the right set of enablers to counter those barriers (Hussain \& Malik, 2020).

Previous studies conducted on CSCM take various industries into account; however, the pharmaceutical industry has rather been neglected in this regard (Ang et al., 2020). The literature further lacks the usage of both qualitative and quantitative techniques to provide a supporting framework for the pharmaceutical industry (Lahane et al., 2020). Hence, this paper aims to fill in that gap by devising a supporting model that would facilitate the particular industry in adopting the CSCM model. To achieve the aforementioned goal, the study in the first phase would identify the barriers the pharmaceutical industry faces in adopting the CSCM approach. To counter those barriers, the study in the second phase would identify enablers that would facilitate the industry in achieving its targets. To analyse the identified barriers and enablers, the study subsequently uses a new hybrid methodology based on F-FUCOM and FQFD approach. The F-FUCOM approach would be used to prioritize the barriers (WHATs), whereas the FQFD approach would be used to rank the enablers (HOWs).

In Sect. 2, the literature review will be discussed, whereas Sect. 3 would comprise data collection and methodology. Lastly, Sects. 4 and 5 would consist of results and discussion and conclusion, respectively.

\section{Literature review}

With increasing levels of pollution and global warming, the world is moving towards the adoption of more sustainable practices (Khan et al., 2020a, 2020b). The concept of CE has achieved more popularity in recent times because of its potential in achieving the targets of SDGs (Geissdoerfer et al., 2017). The incorporation of the CE approach in the supply

\footnotetext{
3 https://www.cleanroomtechnology.com/news/article_page/Opinion_Circular_economy_in_pharmaceut ical_production_plants/162646.
} 
chain operations of the construction industry has shown significantly low levels of carbon emissions along with an increase in economic growth (Nasir et al., 2017). The adoption of the CSCM approach comes with certain barriers in the implementation process that needs the right set of enablers to overcome those barriers (Pan et al., 2015). For example, the lack of support or collaboration between the supply chain managers was found to be the biggest impediment in implementing CSCM in the food industry of China (Farooque et al., 2019). Government plays a huge role in the implementation of CE practices. In particular, friendly policies, laws, risk reduction through tax relaxations, and responsible governance can help organizations to a greater extent (Govindan \& Hasanagic, 2018).

Industries in developing countries are also incorporating $\mathrm{CE}$ practices into their organizations. However, developing countries face more challenges as compared to the developed nations because they have less technological know-how and modern infrastructure (Mangla et al., 2018). The same is evident from a case in India, where 24 obstacles were identified in incorporating CSCM in the plastic industry. The resultant barriers were ranked using the fuzzy analytical hierarchal process (AHP). The topmost barrier found as a result was the lack of tax incentives and poor regulations to protect the environment (Khandelwal \& Barua, 2020). Similarly, a total of 24 barriers were identified in adopting the CSCM approach in the household appliance company. The study further provides enablers in overcoming those barriers. The results of the study suggest coordination between supply chain actors to be the most important strategy for the successful adoption of the CSCM in the organization (Bressanelli et al., 2019).

The adoption of CSCM in the pharmaceutical is a challenging task because of the complex supply chain nature associated with the particular industry. The complex nature of the PSC is because of its relation with human life and the involvement of many stakeholders. This as a result hinders researchers to investigate the particular avenue (Singh et al., 2016). Current linear supply chains in the pharmaceutical sector contribute to significant waste generation which is detrimental to both human health and the environment (Su et al., 2021). Therefore, the waste generated because of the current unsustainable waste management practices needs to be minimized and recycled in the best possible manner. The industry needs the adoption of closed-loop supply chains, which would help in the expired medication being disposed of, remanufactured, or recycled accordingly. However, there are several impediments the industry faces in the adoption of closed-loop supply chains. These challenges are in the shape of competition, customer demand, and a diverse flow of endof-life medicines (Sazvar et al., 2021). The irresponsible behaviour of the consumer, e.g. improper disposal of medicines and leaving the medicines to get expired at homes contributes to unnecessary waste being generated. To solve this problem, return-back programs need to be encouraged, which would make sure the medicines are treated, donated, or recycled accordingly (Ariffin \& Zakili, 2019). The minimization of waste in the PSC can be achieved through the RL infrastructure whose aim should be to recover the expired, end-oflife along with the extra medicines in the inventory holdings with the end retailer (Abbasi \& Farooquie, 2018). To achieve transparency, facilitate sustainability, and a more personalized PSC, the industry needs to adopt new technologies in the realm of industry 4.0 (Ding, 2018).

Recent studies in the literature focus more on the green supply chain management (GSCM) in the pharmaceutical industry. One such study focuses on the pharmaceutical industries of India by identifying top risks for adopting GSCM practices using the fuzzy AHP technique (Kumar et al., 2019). The same concept has been addressed by utilizing the fuzzy technique for order preference by similarity to the ideal solution (TOPSIS) and decision-making trial and evaluation laboratory (DEMATEL) approach to rank 
the barriers in adopting GSCM in the pharmaceutical industry. Findings suggest lack of knowledge regarding environmental benefits, lack of knowledge of green production, and lack of environmental regulations to be the topmost barriers (Shahin et al., 2019). Supporting regulations in implementing green practices was found to be the topmost enabler in implementing green practices in the pharmaceutical industry (Dhull \& Narwal, 2016). However, to achieve the SDGs and further minimization of waste, the industry needs to integrate the concept of $\mathrm{CE}$ in its supply chain management operations. Incorporating CSCM in pharmaceutical companies would bring more sustainability in the entire product life cycle (Ang et al., 2020).

To provide a supporting framework for the pharmaceutical industry in the successful adoption of the CSCM approach, the study in the first phase would identify barriers that impede the industry in transitioning towards the new paradigm. The resultant identified barrier would then be prioritized using a new fuzzy MCDM approach. There are numerous MCDM approaches being used for calculating weights of criteria, e.g. Best Worst Method (BWM), Step-wise Weight Assessment Ratio Analysis (SWARA), Preference Ranking Organization Method for Enrichment of Evaluations (PROMETHE), Elimination Et Choice Translating Reality (ELECTRE), Weighted Aggregated Sum Product Assessment (WASPAS), and the very famous AHP. However, the technique employed in this study is FUCOM, which is a novel MCDM technique formulated by Dragan Pamucar in 2018. The technique aims to act as a model to evaluate the decision-makers in the best possible manner for determining the weight coefficients of criteria (Pamučar et al., 2018). This study used the newly developed fuzzy FUCOM approach formulated by Fatih Ecer and Dragan Pamucar in 2020 (Ecer \& Pamucar, 2020). The robustness and validity of the novel MCDM approach have been determined by comparing it with some of the most powerful MCDM techniques such as fuzzy AHP and fuzzy BWM. The F-FUCOM technique is a hassle-free approach that produces a lesser pairwise comparison of criteria, giving more reliable and consistent results as compared to the previously developed MCDM techniques. The incorporation of the fuzzy set theory in the FUCOM technique further increases its validity and reliability (Tang et al., 2021).

The FUCOM approach in numerous studies has been primarily used for determining the weights of criteria. For example, the most optimal way of recycling cleaning solutions in the glove manufacturing industry uses a combination of the FUCOM and VIKOR approaches (Ong et al., 2021). The FUCOM approach has been further integrated with the COmbined Distance-based ASsessment method (CODAS) for the selection of the most suitable landfill site selection in Libya (Badi \& Kridish, 2020). Moreover, the selection of the most sustainable supplier uses the FUCOM approach for allocating weights to the criteria (Durmić et al., 2020). More recently, the F-FUCOM approach has been used in combination with fuzzy Measurement Alternatives and Ranking according to the COmpromise Solution (MARCOS) approach to select the most sustainable mode of transportation in the USA (Pamucar et al., 2021). To achieve sustainable transportation, the F-FUCOM has been integrated with other MCDM approaches such as fuzzy PIPRECIA (pivot pairwise relative criteria importance assessment) and fuzzy MARCOS (measurement of alternatives and ranking according to compromise solution). The results achieved from the integrated approach were then compared to other MCDM approaches such as fuzzy SAW and fuzzy WASPAS. Through sensitivity analyses, the adopted hybrid methodology provided more powerful results as compared to other MCDM approaches (Blagojević et al., 2021). The F-FUCOM approach has been additionally integrated with CRITIC (The CRiteria Importance through Intercriteria Correlation), DEA (Data Envelopment Analysis), and fuzzy MARCOS to achieve 
traffic safety. The results of which have been validated through sensitivity analysis by comparing them with other approaches (Simić et al., 2020).

In the second step of the study, the prioritized barriers evaluated by the F-FUCOM technique would then be utilized in the House of Quality (HOQ) using the FQFD approach. The QFD tool was firstly used in the Mitsubishi heavy industry in 1972 (Hauser, 1993). QFD is generally used in developing a new product, translating customer's voices or requirements "WHATs" by utilizing engineering characteristics, i.e. "HOWs" (Liu, 2009). The particular approach is popular for its utilization in product design and is widely used as a decision-making tool in the development of new frameworks (Osorio-Gómez et al., 2017). The FQFD technique has been employed in Italian mechanical industries, to enhance the customer's experience with logistic services (Bottani \& Rizzi, 2006). The same approach has been further used to improve the design and the overall performance of a vehicle (Chen \& Ngai, 2008). Moreover, developing lean attributes and strategies for the Indian switch manufacturing industry uses the same approach (Vinod \& Chinta, 2011). It has also been used to develop the best e-learning experience for effective distance education by involving experts to find the right characteristics and strategies (Kazancoglu \& Aksoy, 2011). The FQFD has also been employed to find the best supplier for a complete clutch manufacturing industry (Bevilacqua et al., 2006) The technique has also been used in enhancing supply chain reliability, keeping customer's needs, and design specifications into account (Sohn \& Choi, 2001). Similarly, identifying important logistic requirements and supply chain management strategies for a dairy company in turkey utilizes the same approach (Ayağ et al., 2013). Moreover, for a resilient supplier selection in the manufacturing system, QFD has been integrated with other MCDM techniques such as AHP, and TOPSIS to identify the general features of selection criteria (Pramanik et al., 2017). Similarly, a combination of AHP-QFD is also employed in selecting the best supplier for a Precision Machine High-Pressure Die Casting components company (Rajesh \& Malliga, 2013). In addition to this, the fuzzy AHP-QFD-PROMETHEE approach has been used to identify lean attributes and enablers to achieve lean production in the automotive industry (Roghanian \& Alipour, 2014).

The PSCs have a considerable impact on the economic and environmental indicators and so ensuring sustainability in the particular sector is of eminent importance. However, to achieve this goal a joint effort by all the stakeholders have to be made to minimize waste in the particular sector (Smale et al., 2021). The current COVID-19 pandemic has, even more, highlighted the importance of PSCs (Sazvar et al., 2021). However, through a rigorous literature review, it has been determined that the particular area has rarely been addressed in the literature particularly when it comes to the RL infrastructure in the PSCs (Campos et al., 2017). To achieve all the metrics of sustainability the pharmaceutical industry has to adopt the concept of CSCM. For this purpose, this study uses a hybrid combination of F-FUCOM and FQFD to achieve the aforementioned goal. The integration of the F-FUCOM the FQFD has numerous advantages. In the first phase the reliable MCDM approach, i.e. F-FUCOM would ensure the prioritization of barriers for its use as WHATs in the HOQ. The prioritization of barriers would help the pharmaceutical industry to systematically overcome any impediments in the application of the CSCM approach. In the second part of the study, the prioritized barriers in the first phase would be used as WHATs in the HOQ. Whereas the identified enablers would be considered as HOWs in the HOQ and would be ranked accordingly through the FQFD approach. The ranked enablers as a result would facilitate the pharmaceutical industry in transitioning towards the CSCM approach. The significance of the FQFD is its ability to determine the relationship between WHATs and HOWs and the correlation between HOWs. Assessing the 
relationship between the WHATs and HOWs would remove any possible risk of misalignment between barriers and enablers. Here the role of experts in assessing the relationship and correlation matrices is of paramount importance (ÇIL \& EVREN, 1998). In addition to this, the roof of the HOQ would ensure the computation of possible correlations between enablers (HOWs), helping to achieve the best possible results. Whereas, the fuzzy set theory used during the assessment process in both the steps would further ensure removing any ambiguity while collecting data from the experts (Bottani, 2009). The newly developed fuzzy hybrid approach and its application in the pharmaceutical industry in achieving the CSCM approach are both novelties of this study.

\section{Data collection and methodology}

The data collection process starts with the identification and adoption of barriers from an extensive literature review. These barriers were collected from articles related to CE, CSCM, GSCM, sustainable supply chain management, closed-loop supply chain, and waste management in pharmaceutical industries. The next step was to remove any kind of redundancy and shortlist the most critical barriers among an extensive list of collected barriers from the literature. For this experts from the pharmaceutical industries, particularly the supply chain managers and the top management of multinational companies were taken on board. The aim of these interactions was just to validate the secondary data and identify real-world barriers that the pharmaceutical industries could face in adopting the new approach. These were semi-structured interviews that were conducted with some of the most renowned pharmaceutical companies such as Pfizer, Martin Dow, Servier, and Getz pharma. The total number of interviews conducted were eight. From each company, one supply chain manager and a member of the top management were interviewed. The interviews contained questions like discussing the supply chain operations of the respective companies. The concepts of $\mathrm{CE}$ and its role in supply chain management were also discussed. The existing sustainability models adopted and practiced by the respective companies were also discussed. They were then subjected to the list of barriers that were already collected from the secondary literature. Their role in reviewing the extensive list of barriers was to identify and shortlist the most critical barriers along with removing any chances of redundancy. After the eight rounds of interviews, the short-listed barriers were then subjected to a mini Delphi approach. The role of which was to shortlist the most repeated barriers among all the conducted interviews. The finalized list of identified barriers along with their descriptions is given in Table 1.

After the finalization of the barriers, the second part of the data collection process was to identify enablers from the secondary literature that would help the pharmaceutical companies in adopting the CSCM approach. The enablers were collected from the literature using the same set of articles mentioned previously for collecting barriers. The extensive list of enablers were then finalized with the help of the same group of experts as mentioned earlier. Here again, the role of the experts was to shortlist and identify the most effective enablers. The finalized list of enablers and their explanation is given in Table 2.

After the finalization of barriers and enablers, the next step was to analyse them using the hybrid methodology. In the first part of the methodology, the F-FUCOM approach was used to prioritize the barriers with the help of experts mentioned in Table 1. For this, a survey form was created where the experts were requested to rate the barriers using a fivepoint fuzzy Likert scale given in Table 4. For this, data were collected from a total of 21 
Table 1 Identified barriers from experts and literature

\begin{tabular}{|c|c|}
\hline Barriers & Explanation \\
\hline $\begin{array}{l}\text { B1. Lack of financial resources and funding (Veleva } \\
\text { \& CueJr, 2019) }\end{array}$ & $\begin{array}{l}\text { High investment and production cost for involving in } \\
\text { green practices and adopting CE principles }\end{array}$ \\
\hline $\begin{array}{l}\text { B2. Limited expertise, technology, and information } \\
\text { (Veleva et al., 2018) }\end{array}$ & $\begin{array}{l}\text { Lack of knowledge, skilled workers, technology, } \\
\text { research and development, and information sharing } \\
\text { among pharma industries }\end{array}$ \\
\hline B3. Organizational culture and management & $\begin{array}{l}\text { Lack of support from top management and weak or } \\
\text { non-existent circular economy models }\end{array}$ \\
\hline B4. Social challenges (Lahane et al., 2020) & $\begin{array}{l}\text { Lack of knowledge and support of the public towards } \\
\text { circular economy practices }\end{array}$ \\
\hline B5. Market challenges (Lieder \& Rashid, 2016) & $\begin{array}{l}\text { Lack of availability of suppliers of quality and green } \\
\text { raw materials and competition among pharma } \\
\text { industries }\end{array}$ \\
\hline $\begin{array}{l}\text { B6. Lack of coordination and collaboration between } \\
\text { supply chain actors (Ding, 2018) }\end{array}$ & $\begin{array}{l}\text { Lack of cooperation among the entire supply chain } \\
\text { network including manufacturers, wholesalers, GPs, } \\
\text { pharmacies, and patients }\end{array}$ \\
\hline $\begin{array}{l}\text { B7. Lack of production and inventory planning } \\
\text { (Uthayakumar \& Priyan, 2013) }\end{array}$ & $\begin{array}{l}\text { Lack of demand forecasting disturbs the demand and } \\
\text { supply gap, resulting in overproduction and expired } \\
\text { medications }\end{array}$ \\
\hline $\begin{array}{l}\text { B8. The low shelf life of medicines (Alshemari } \\
\text { et al., 2020) }\end{array}$ & Low quality and quick expiry of the medicines \\
\hline $\begin{array}{l}\text { B9. Difficulty in the visibility of the supply chain } \\
\text { (Sara et al., 2018) }\end{array}$ & $\begin{array}{l}\text { The complexity of the pharmaceutical supply chain } \\
\text { makes it difficult to monitor the entire supply chain }\end{array}$ \\
\hline $\begin{array}{l}\text { B10. Ineffective segregation of waste (Viegas et al., } \\
2019\end{array}$ & $\begin{array}{l}\text { Ineffective segregation of waste in the pharma indus- } \\
\text { try and hospitals makes it difficult to further treat } \\
\text { the waste }\end{array}$ \\
\hline
\end{tabular}

experts. The highest number of years among the respondents was 25 years, whereas the least was 2 years. The average experience of the experts was 5.75 years. The list of experts and their corresponding numbers are given in Table 3.

\subsection{Fuzzy set theory}

The data collected for prioritizing the barriers were in linguistic variables, the range of which was from very low to very high. After the data collection process, the linguistic variables are then transformed into their respective fuzzy numbers. The fuzzy set theory was devised by Lotfi Asgharzadeh in 1965 (Zadeh, 1965). The fuzzy set theory helps capture ambiguity and vagueness while collecting data from the respondents.

Let us consider $(S)$ having a member set containing $(z)$; then, the fuzzy set having the ordered pair is shown in Eq. (1),

$$
H=\left\{\left(z, \mu_{f}(z)\right) \mid z \in S .\right.
$$

The function $(z) \mu H$ shows the amount of membership of $(z)$ belonging to the fuzzy set of $H$. The range between $[0,1]$ contains real numbers that hold a minimum value of 0 and a maximum value of 1 . Some of the shapes associated with the fuzzy numbers are triangular, bell, and trapezoid forms. However, for simplicity, this paper uses triangular fuzzy numbers. The three distance variables can be expressed through the constants, i.e. $(u, v, x)$, given in Fig. 1. 
Table 2 Identified enablers from experts and literature

Enablers
E1. Industrial symbiosis (Maranesi \& Giovanni,
2020)
E2. Blockchain technology (Bocek et al., 2017)
E3. Pharma Industry 4.0 manufacturing (Ding,
2018)
E4. Appropriate training \& development programs
(Zaid et al., 2018)

E5. RL infrastructure (Viegas et al., 2019)

E6. Awareness campaigns for the public (Hartley et al., 2020)

E7. Legislative framework

(Roberta et al., 2018)

E8. Competent research and development team (Veleva et al., 2018)

E9. Using biodegradable and smart packaging (Meherishi et al., 2019); (Hui et al., 2020)

E10. Utilizing green chemistry/engineering (Roschangar et al., 2015)

E11. Using bio-economy (Viegas et al., 2019)

E12. Drugs donations (Viegas et al., 2019)

\section{Explanation}

Cross-collaboration between industries in exchanging resources to achieve resource productivity

Using blockchain technology to enhance visibility across the entire supply chain

Industry 4.0 helps in sustainable development, leading towards a more robust, intelligent, and customized pharma industry

Training employees, typically supply chain managers about CE models and principles

An RL infrastructure that does not only collect expired medications/medical equipment but also non-expired medicines for further recycling/reuse or donations

Educating medical practitioners, pharmacists, and consumers towards $\mathrm{CE}$ practices

Supporting legislation regarding the adoption of CE principles

Bringing innovations, continuous improvements, and sustainability in medications

Using biodegradable packaging because of their user and eco-friendly and nontoxic advantages, also using smart packaging for easy medicine detectability

Using green chemistry/engineering in the upstream and downstream part of the supply chain

The surplus medicines or the end-of-life and end-ofuse (EOU/EOL) medicines can be used for several purposes involving the use of biotechnology

The donation of non-expired medicine to the needy individuals
Table 3 Expert's profile and their number

\begin{tabular}{lc}
\hline Expert's profile & $\begin{array}{l}\text { Associ- } \\
\text { ated } \\
\text { number }\end{array}$ \\
\hline Supply chain managers from pharmaceutical industries & 9 \\
Medical experts & 7 \\
Academia related to supply chain & 5 \\
Total & 21 \\
\hline
\end{tabular}

The membership of the fuzzy numbers is given by Eq. (2):

$$
\mu b(z)=\left[\begin{array}{c}
z-u / v-u \quad u \leq z \leq v \\
x-z / u-v \quad v \leq z \leq x \\
0 \text { otherwise }
\end{array}\right.
$$


Table 4 Fuzzy scale (source: Khan et al., 2020a, b)

\begin{tabular}{ll}
\hline Linguistic variables & Fuzzy number \\
\hline Very Low (VL) & $(1,1,3)$ \\
Low (L) & $(1,3,5)$ \\
Medium (M) & $(3,5,7)$ \\
High (H) & $(5,7,9)$ \\
Very High (VH) & $(7,9,9)$ \\
\hline
\end{tabular}

Fig. 1 Fuzzy triangular numbers

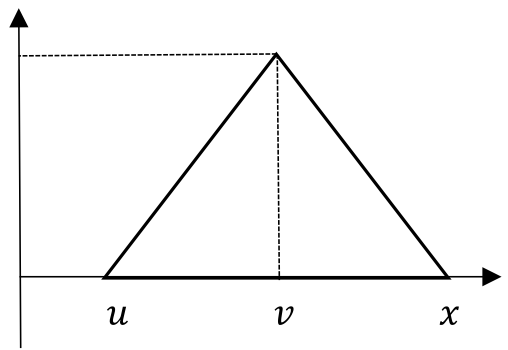

where $u, v$, and $x$ are integers, having an order of $u<v<x$. The value of $z$ at $v$ gives the maximal value of $\mu_{\mathrm{f}}(z)$, i.e. $\mu_{\mathrm{f}}(z)=1$, whereas the value of $z$ at $v$ generates the minimum value of $\mu_{\mathrm{f}}(\mathrm{y})$, i.e. $\mu_{\mathrm{f}}(z)=0$, holding the least expected value of the data to be evaluated. The constant, i.e. uandv corresponds to the lower and upper bounds, respectively. The range between $u a n d x$ showcases the degree of ambiguity in the data. The lower degree of the interval there is between $[u, x]$ in the collected data the lower there is fuzziness involved and vice versa. The distance between any two triangular fuzzy numbers such as $\beta=u, v, x$ and $\gamma=u, v, x$ can be calculated using Eq. (3):

$$
d(\beta, \gamma)=\sqrt{\left(\frac{1}{3}\right)\left[u-u^{\prime}\right]^{2}+\left[v-v^{\prime}\right]^{2}+\left[x-x^{\prime}\right]^{2}}
$$

\subsection{F-FUCOM technique}

The FUCOM approach has been formulated by Dragan Pamucar in 2018 to calculate the weights of criteria. The approach focuses on the principle of pairwise comparison of criteria along with validation of results through deviation from maximum consistency. The advantage of using the adopted MCDM approach is its attribute of generating a lesser pairwise comparison of criteria, i.e. only ( $n-1)$. Its simple mathematical formulation further ensures the verification of results by defining the deviation from maximum consistency through the development of transitivity. The results achieved through the particular approach eliminate any possibility of redundancy in the pairwise comparison of criteria, giving more consistent findings (Pamučar et al., 2018). To further increase the reliability and efficiency of the FUCOM approach, the two scientists, i.e. Fatih Ecer and Dragan Pamucar further incorporated the fuzzy logic in the methodology to make it more reliable (Ecer \& Pamucar, 2020). 
The mathematical steps involved in the F-FUCOM approach are given below (Ecer \& Pamucar, 2020):

Step 1: The first step is the determination of decision criteria. Suppose that there are $n(m=1,2 \ldots n)$ criteria, which is represented by the set $C=\left\{C_{1}, C_{2} \ldots C_{n}\right\}$.

Step 2: In the second step, linguistic variables, given in Table 1, are used by the decision-makers to assess the criteria. The decision-makers are asked to allocate weights to the criteria according to their judgment. The criterion that is given more significance is ranked first, whereas the one given the least preference is ranked the last. Hence, a ranked criterion according to the expert's opinion is formulated in the form of an MCDM model.

$$
C_{m(1)}>C_{m(2)}>\cdots>C_{m(p)}
$$

The $m$ in Eq. (4) represents the rank of criteria. An equality sign is used between the criteria if two criteria have the same ranking.

Step 3: The criteria in this step are compared to each other with the help of the scale given in Table 4. The comparison is carried out based on the criterion having the highest significance. Hence this way, a fuzzy criterion significance $\left(\varpi c_{m(n)}\right)$ is made for the criteria ranked in Step 2. Since the first criterion is compared with itself (its significance is $\left.\varpi c_{m(1)=E I}\right)$, now, $n-1$ of the remaining criteria should be carried out. A fuzzy comparative significance $\emptyset_{n /(n+1)}$ is found by using Eq. (5):

$$
\emptyset_{p /(p+1)}=\frac{\varpi c_{m(p+1)}}{\varpi c_{m(p)}}=\frac{\left(\varpi_{c_{m(p+1)}}^{u}, \varpi_{c_{m(p+1)}}^{v} \varpi_{c_{m(p+1)}}^{x}\right.}{\varpi_{c_{m(p)}}^{u}, \varpi_{c_{m(p)}}^{v}, \varpi_{c_{m(p)}}^{x}}
$$

Hence, a fuzzy vector of the comparison criteria is achieved by applying Eq. (6):

$$
\emptyset=\emptyset_{1 / 2}, \emptyset_{2 / 3}, \ldots \emptyset_{p /(p+1)}
$$

Step 4: In this step, the fuzzy weights of the criteria $\left(w_{1}, w_{1}, \ldots, w_{n}\right)^{T}$ are calculated. The following two conditions should be satisfied with the final values of the weight coefficient:

First condition: The ratio of the weight coefficient of the evaluated criteria $\left(C_{m(p)}\right.$ and $\left.C_{m(p-1)}\right)$ should equate to the comparative significance $\left(\emptyset_{j /(n+1)}\right)$ given in Step 2:

$$
\frac{w_{m}}{w_{m+1}}=\emptyset_{m /(m+1)}
$$

Second condition: Along with the condition defined in Eq. (6), the resultant values of the weight coefficient should satisfy transitivity $\emptyset_{m /(m+1)} \times \emptyset_{m+1 /(m+2)}=\emptyset_{m /(m+2)}$, i.e. $\frac{w_{m}}{w_{m+1}} \times \frac{w_{m+1}}{w_{m+2}}=\frac{w_{m}}{w_{m+2}}$. Hence, the second condition becomes:

$$
\frac{w_{m}}{w_{m+2}}=\emptyset_{m /(m+1)} \times \emptyset_{m+1 /(m+2)}
$$

Minimum DMC, i.e. $\chi=0$ is only satisfied if Eq. (8) among weight coefficients is satisfied. Hence, one can say that $\frac{w_{m}}{w_{m+1}}-\emptyset_{\frac{m}{m+1}}=0$ and $\frac{w_{m}}{w_{m+2}} \emptyset_{m /(m+1)} \times \emptyset_{m+1 /(m+2)}=0$; for such results, the DMC is $\chi=0$. For these conditions to be satisfied, the values of the weight coefficient $\left(w_{1}, w_{1}, \ldots, w_{n}\right)^{T}$ must fulfil the condition such that $\left|\frac{w_{m}}{w_{m+2}}-\emptyset_{m /(m+1)}\right| \leqslant \chi$ and $\left|\frac{w_{m}}{w_{m+2}}-\emptyset_{m /(m+1)} \times \emptyset_{m+1 /(m+2)}\right| \leqslant \chi$ with the minimization of value $\chi$. 
Table 5 Respondents involved in assessing the HOQ

\begin{tabular}{ll}
\hline Experts profile & Number \\
\hline Supply chain managers from pharma industries & 3 \\
Medical experts & 2 \\
Academia related to supply chain & 2 \\
Total & 7 \\
\hline
\end{tabular}

\begin{tabular}{ll}
\hline Magnitude of relationship & Fuzzy number \\
\hline Strong & $(0.7 ; 1 ; 1)$ \\
Medium & $(0.3 ; 0.5 ; 0.7)$ \\
Weak & $(0 ; 0 ; 0.3)$ \\
\hline
\end{tabular}

Magnitude of correlation

Fuzzy number

variables for assessing correlation matrices (source: Bottani \& Rizzi, 2006)

\begin{tabular}{ll}
\hline Strong Positive (SP) & $(0.7 ; 1 ; 1)$ \\
Positive (P) & $(0.5 ; 0.7 ; 1)$ \\
Negative (N) & $(0 ; 0.3 ; 0.5)$ \\
Strong Negative (SN) & $(0 ; 0 ; 0.3)$ \\
\hline
\end{tabular}

The steps mentioned above can now be used to determine the final nonlinear models given by equations $\mathrm{A}_{9}$ and $\mathrm{A}_{10}$ in Appendix $\mathrm{A}$ of this paper.

\subsection{The FQFD approach}

After the prioritization of the barriers (WHATs) using F-FUCOM, the FQFD methodology was then used to rank the enablers (HOWs) using the HOQ. The FQFD methodology used in this study has been developed by Eleonora Bottani for achieving agility in companies (Bottani, 2009). The same fuzzy QFD approach has been further integrated with fuzzy AHP to achieve food supply chain leanness (Zarei et al., 2011). A more recent hybrid approach uses the novel MCDM approach, i.e. FUCOM and fuzzy QFD in achieving healthcare resilience in the wake of pandemics (Khan et al., 2021). However, this study integrates the fuzzy logic approach with FUCOM methodology along with FQFD to provide a supporting framework for the adoption of CSCM in the pharmaceutical industry. A total of seven experts were involved in assessing the HOQ. The expert's profile of the respondents is given in Table 5 .

The fuzzy linguistic variables used in this study to assess the relationship between WHATs and HOWs and the correlation between HOWs are given in Tables 6 and 7, respectively.

The addition and multiplication of treating the fuzzy numbers are shown in Eqs. (9) and (10) and are given below, respectively (Chien \& Tsai, 2000):

If $R=(h 1, i 1, j 1)$ and $S=(h 2, i 2, j 2)$ are two fuzzy numbers, then 


$$
\begin{aligned}
& \text { Fuzzy addition : } R+S=(h 1+h 2, i 1+i 2, j 1+j 2) \\
& \text { Fuzzy multiplication : } R \times S=(h 1 \times h 2, i 1 \times i 2, j 1 \times j 2)
\end{aligned}
$$

The proposed hierarchy and the HOQ developed for this study are given in Figures 3 and 4 in Appendix A of this paper.

After the assessment of relationship and correlation matrices, the next step was to analyse the resultant HOQ using the steps associated with the FQFD (Zarei et al., 2011).

Step1: In the first step, the relative importance, i.e. $R_{i j}$ is calculated using Eq. (11):

$$
R I_{j}=\sum_{i=1}^{n} W i \times R i j \quad \text { where } j=1, \ldots, n
$$

Step 2: Priority weights of the enablers are to be calculated in this step, using Eq. (12).

$$
P I_{j}^{*}=R_{i j}+\sum_{e=j} T_{e j} \times R_{i j}
$$

where $T_{e j}$ represents the rooftop, i.e. the triangular portion in the HOQ shown in Fig. 4 in Appendix A of this paper.

Step 3: In this step, the resultant fuzzy weights are normalized using the fuzzy set algebra. The normalized $\left(\mathrm{NPI}_{j}^{*}\right)$ is found by dividing each priority weight $\left(\mathrm{PI}_{j}^{*}\right)$ by the highest $\mathrm{PI}_{j}^{*}$ (Zimmermann, 1991).

Step 4: In the final step, resultant normalized $N P I_{j}^{*}$ is to be de-fuzzified using Eq. (15):

$$
\text { Defuzzification }=(a * b * c)^{1 / 3}
$$

The resultant de-fuzzified values are subsequently ranked based on the significance or weightage of the respective enablers. For example, the enabler holding the most weightage would be ranked first, whereas the one holding the least weightage would be ranked the last.

\subsection{Results and discussion}

The identified barriers to the adoption of CSCM in the pharmaceutical industry in the first step were subjected to the F-FUCOM approach. Experts were involved in assessing the barriers using a five-point fuzzy Likert scale given in Table 4. The next step involved the pairwise comparison of the barriers. After the pairwise comparison of barriers, the next step was to satisfy a set of two conditions to move to the next step. The first condition determines the comparative significance, which is found by dividing the second barrier with the first barrier, and so on using Eq. (7). The second condition should satisfy the transitivity, i.e. the resultant fuzzy weight from condition one is multiplied among each barrier using Eq. (8). Using equations $A_{9}$ and $A_{10}$, the achieved nonlinear model is solved through the LINGO software. The resultant list of prioritized barriers in descending order is given in Table 8 .

From Table 8, "lack of financial resources and funding" is prioritized to be the biggest impediment to the pharmaceutical companies in transitioning towards the CSCM approach. Pharmaceutical industries are capital intensive because the industry is heavily based on rigorous research and development practices. The adoption of CE principles though in the 
long run would help attain sustainability, but the initial cost of investment in clean and lean production practices and technologies is expensive (Ding, 2018). Investing in a closed-loop supply chain in the form of an RL infrastructure that focuses on take-back programs, reuse, and recycle of pharmaceutical products and medicines is though beneficial for the companies, in the long run, is however costly in the short run. (Kongar et al., 2015). Lack of financial resources or funding is however considered as a most prominent impediment in achieving a sustainable closed-loop supply chain (Abbas, 2018). The second barrier prioritized by the experts is "market challenges". The industry faces market challenges in the shape of a lack of cooperation, collaboration, and information sharing among pharmaceutical industries. Collaboration in terms of exchanging expertise, information, and green raw materials would help the overall industries in being more sustainable. However, the nonuniformity in the market gives rise to competition in the market hindering the companies to move towards sustainability. Here, the government can play its role by formulating legislation that goes in the favour of these industries. Supporting legislation can be in the form of tax incentives regarding green and cleaner production practices (Singh et al., 2018). Lastly, the third most critical barrier prioritized by the experts is "lack of coordination and collaboration within the supply chain network". The complexity of the PSC makes it difficult for the supply chain actors to monitor the entire supply chain especially during the RL operations of the company (Kongar et al., 2015). During uncertain times, ensuring a proper coordination plan especially during a closed-loop supply chain in the pharmaceutical companies is usually a challenge. Keeping the context of CE into consideration the collection of leftover pharmaceuticals usually contains chemicals, if not managed properly can be hazardous to both the environment and human beings. To overcome these challenges, a proper coordination plan in the collection of such products is essential (Motlagh et al., 2020). It is estimated that the pharmaceutical companies can collect $28 \%$ of more products from the market for further reuse or recycling purposes if they coordination their reverse operations efficiently (Weraikat et al., 2016a, b).

After the prioritization of barriers, the resultant barriers were then treated as (WHATs) in the HOQ, whereas the enablers were treated as (HOWs) in the HOQ using the FQFD approach. In this case, experts were asked to determine the relationship between the barriers and enablers and the correlation between the enablers using the fuzzy linguistic variables given in Tables 6 and 7, respectively. The first step in the analysis was to determine the relative importance by multiplying the weights of WHATs with that of HOWs using Eq. 11. In the second step, priority weights were determined using Eq. 12. In the third step, the priority weights determined in step 2 were then normalized by dividing each priority weight with that of the highest value of priority weight. The normalized weights, as a result, were then de-fuzzified using Eq. 13, to rank the resultant enablers. The complete HOQ along with the achieved results are given in Table 9.

As evident from the HOQ in Table 9, "industrial symbiosis" has been ranked to be the top-most effective enabler in adopting CSCM in the pharmaceutical industry by the experts. A sustainable supply chain needs to focus on environmental management, product stewardship, RLs, recycling, reuse, and remanufacturing which could be made possible through the adoption of industrial ecology and industrial symbiosis. A symbiotic relationship among industries helps each other to manage waste in the best possible manner helping to achieve all metrics of sustainability. The same argument has been validated through a case study on a large distributor in the UK, in which through an industrial symbiotic network the company achieved environmental sustainability along with an overall sustainable closed-loop supply chain (Leigh \& Hong Li, 2015). Governments play a pivotal role in creating these symbiotic linkages between organizations, just like the UK is doing with its 
National Industrial Symbiosis Programme (NISP). These types of initiatives and programs can pave the way towards a more circular-oriented economy (Abreu \& Ceglia, 2018). Countries like China are also working towards the same goal through their eco-industrial parks (Wen \& Meng, 2015). Among pharmaceutical industries, symbiotic supply chains are not a new concept. Some of the symbiotic relationships have been seen in Barceloneta, Puerto Rico, where the top leading pharmaceutical companies like Abbot, Pfizer, Merck, and Bristol-Myers Squibb are operational. These relationships extend in the exchange of by-products such as spent solvents, which are sold to paint manufacturers. From the wastewater treatment plant, the organic treated sludge is used as fertilizer for growing fodder, whereas the fermentation residue is sold to farmers to feed their livestock. There is also the sharing of wastewater treatment plants among different manufacturers along with cogeneration of energy projects (Ashton, 2018).

From the HOQ in Table 9, the second most effective enabler in adopting CSCM in the pharmaceutical industry is an "RL infrastructure". Pharmaceutical companies do have RL infrastructure but they are mainly involved in retrieving expired medications from the market for further incineration. However, this should not be the only role of the RL infrastructure. The RL infrastructure should be secure enough to ensure any type of counterfeit infiltration of medicines in the supply chain. Enhanced traceability can be ensured through the usage of RFID technology (Kongar et al., 2015). The infiltration of counterfeited medicines can be controlled through a strict penalty by the governments as it is detrimental to both society and the environment. The RL infrastructure can be further employed in the recovery of medicines that have damaged packaging. The retrieval of such medicines has the potential of recovering the full market value of those drugs. Medicines that are in the stage of their EOL should not be left in the pharmacies until their expiry but should be collected and donated to needy individuals accordingly. This as a result would not only reduce wastage of medicines but would also add to the corporate image of the company (Khan \& Subzwari, 2009). The preceding goal can be achieved through take-back programs whose aim should be to ensure the retrieval of such medicines from the sales centres and the public. Incentivizing the public during the take-back drive can help pharmaceutical industries to sell the unexpired medicines at subsidized rates or donate them to undeveloped countries. A case study conducted in the same context suggests that through proper incentivization, the pharmaceutical companies can decrease the rate of uncollected medicines from 18 to $6.5 \%$ (Weraikat et al., 2016a, b). Improving the reverse flows of medicines, i.e. the recycling of the pharmaceutical medicines for later reuse/recycle can economically be very beneficial to the pharma industry. The same benefits have been reported in the case of multi-national pharma companies of Pakistan, where an effective RL management brought significant financial and operational benefits, saving at least $10 \%$ of the total cost of Rs5 billion of the overall RL processes (Khan \& Subzwari, 2009). Through the development in the field of green engineering technologies, scientists are now able to extract API from non-expired or EOL/EOU medicines. The recovery of the API process is over $90 \%$ effective, making it suitable for further formulation development (Hsieh et al., 2017). Effective segregation of medical waste on the consumer level would further ensure sustainable waste management practices such as recycling and reusing products. A good example of this can be the reusing and recycling of the outer packaging or cartage of inhalers (Alshemari et al., 2020). Supporting legislation from the government bodies can be beneficial in improving the overall RL infrastructure, a good example of which can be the supporting laws in Portugal (Niza et al., 2014).

The third most effective enabler that would facilitate the pharmaceutical industries to adopt CSCM is the adoption of "block chain technology" as evident from the HOQ in 
Table 9. There are several processes in the PSC that make it very complex. These processes include the procurement of raw materials, production and inventory planning, forward logistics, RLs, and the involvement of various stakeholders across the whole supply chain network (Singh et al., 2016). To address these challenges, the role of blockchain technology in the PSCs has become of paramount importance. The application of the particular technology would help the industry to digitize their physical assets along with the potential of decentralizing every transaction. It will further aid the industry to efficiently manage their inventory, helping them to identify issues more swiftly, enhance drug recall management, and reduce the overall cost of operations (Clauson et al., 2018). The adoption of blockchain technology in the pharmaceutical industry benefits both the manufacturers and the customers and society in general (Niu et al., 2021). It helps the managers to monitor the drug distribution network, which is particularly helpful in the recalling of counterfeit medicines (Sylim et al., 2018). Certain pharmaceutical products are required to be stored in a specific range of low temperatures, and so if these temperatures are not maintained properly across the supply chain network, companies can face significant losses. It also leads to unnecessary waste being created across the supply chain. To solve this problem, the digitalization of the pharmaceutical cold supply chain would monetarily benefit the manufacturer, with less waste being generated as well (Bamakan et al., 2021). In essence, the adoption of blockchain technology would ensure complete visibility, traceability, and security in the drug supply system that ultimately optimizes the use of medications from the production to the final consumption (Haq \& Esuka, 2018).

Hence, the challenges faced by the pharmaceutical companies in adopting the CSCM such as the lack of financial resources, market challenges, and lack of collaboration within the supply chain network can be surmounted by the adoption of strategies such as industrial symbiosis, RL infrastructure, and block chain technology accordingly. These strategies or enablers would not just ensure environmental sustainability but would also ensure economic sustainability. The aforementioned enabler would not only give a competitive advantage to the companies but would also create employment opportunities. Thus through this way, several targets of SDGs can be achieved. Having said that there are other strategies and practices that can pave the way towards a more sustainable future for the pharmaceutical industry. For example, the waste created by the pharma industry is usually toxic and hence the only way to deal with expired medications is incineration. Therefore, instead of the $3 \mathrm{R}$ approach, i.e. reduce, reuse, and recycle policy, the industry needs to shift towards the $9 \mathrm{R}$ framework of the CE model. The $9 \mathrm{R}$ framework given in Table 10 when adopted would help make the pharmaceutical industry more sustainable (Kirchherr et al., 2017).

Also, the pharmaceutical industry already being heavily regulated on health issues should be further regulated on environmental issues. Most of the supply chain managers during the interview process were unaware of the concept of CSCM. Therefore, informing these managers about the new concept would require training and development programs. The awareness campaigns should be extended towards the consumer level as well. The physicians and GPs should also be trained through workshops and seminars to prescribe the right frequency and quantity of medications to their patients, whereas the patient should adhere to the prescribed medications and refrain from careless attitudes such as abandoning the prescribed treatment. Furthermore, the leftover medicines should not be kept on the shelves until expiry but should be donated to needy individuals. In addition to this, the industry should also focus on shifting towards the use of green engineering both in the upstream, i.e. in the formulation of API, and the downstream, i.e. in the extraction of the useful API from the EOL/EOU medicines. The use of bio-economy in the downstream part of the supply chain would further eliminate waste. Here, the surplus medicine could be 


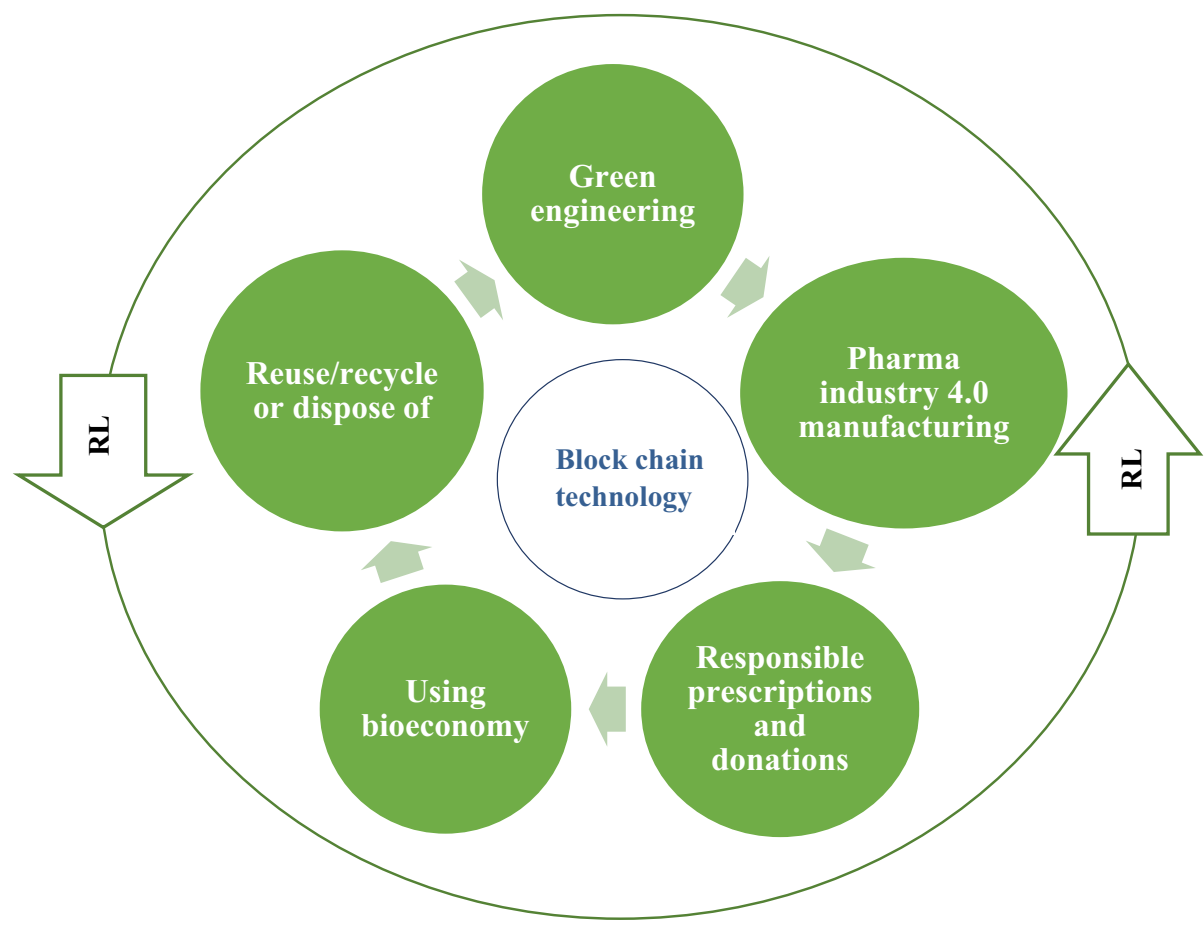

Fig. 2 The CSCM approach in the pharmaceutical industry

Table 8 Prioritized barriers using the F-FUCOM approach

\begin{tabular}{lll}
\hline Prioritized barriers & Fuzzy weights & $\begin{array}{l}\text { De- } \\
\text { fuzzified } \\
\text { weights }\end{array}$ \\
\hline B1. Lack of financial resources and funding & $(0.07,0.15,0.15)$ & 0.1170 \\
B5. Market challenges & $(0.07,0.13,0.13)$ & 0.1048 \\
B6. Lack of collaboration within the supply chain network & $(0.06,0.12,0.12)$ & 0.0928 \\
B2. Limited expertise & $(0.05,0.11,0.11)$ & 0.0866 \\
B10. Ineffective segregation of waste & $(0.05,0.11,0.11)$ & 0.0832 \\
B9. Difficulty in the visibility of supply chain & $(0.04,0.11,0.11)$ & 0.0800 \\
B10. Organization culture & $(0.04,0.10,0.10)$ & 0.0705 \\
B8. Low shelf life & $(0.03,0.10,0.11)$ & 0.0674 \\
B4. Social challenges & $(0.03,0.09,0.09)$ & 0.0665 \\
B7. Lack of production and inventory planning & $(0.03,0.09,0.09)$ & 0.0603 \\
\hline
\end{tabular}

used as a source for raw materials such as phosphate (Carraresi et al., 2018), or perishable products such as food (Frigo \& Lucchini, 2018). The last option under the cleaner production and bio-economy principle would be the destruction of EOL/EOU medicines using methods such as pyrolysis for harnessing energy (Filippis et al., 2012). Figure 2 shows the complete framework for the pharmaceutical industries to eliminate waste and become 


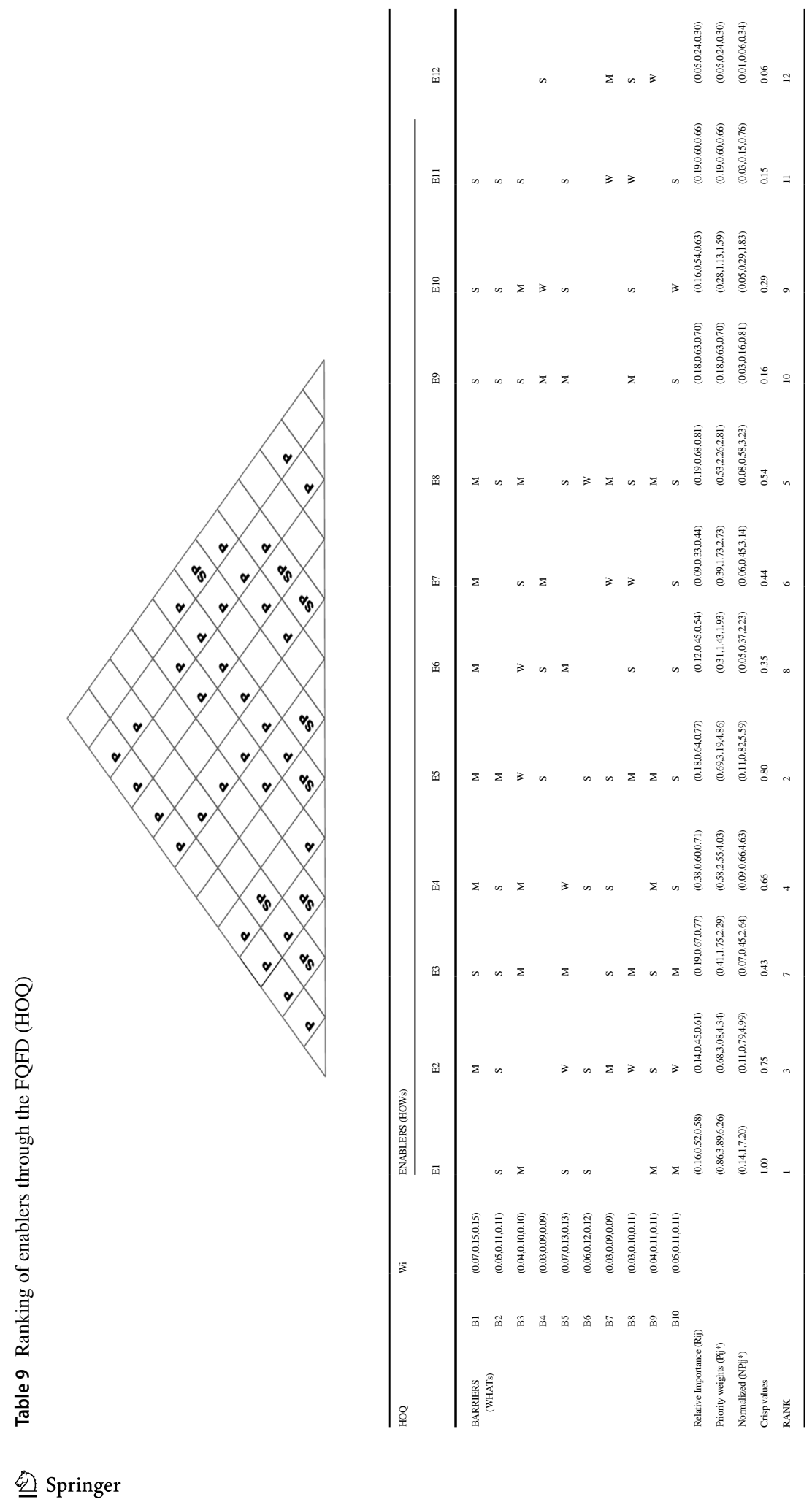


more sustainable. An overall framework of the proposed policy recommendations is given in Fig. 2.

\section{Conclusion}

The curb, the waste generated around the world industries, is moving towards the adoption of CE principles. Recently, there has been a new development in which organizations are working towards the incorporation of $\mathrm{CE}$ principles into their supply chain operations, giving rise to the concept of CSCM. However, there is little literature available when it comes to the incorporation of CSCM in the pharmaceutical industry. The PSCs are fairly complex because of the involvement of several stakeholders. Also, the waste generated by the particular industry is toxic and hazardous which needs proper management. To achieve sustainability, the particular industry needs an effective framework that would help them to minimize its waste and use its resources in the best possible manner. To solve the aforementioned problem, this study aimed to devise a supporting framework that would help the pharmaceutical industry in adopting the CSCM approach. For this purpose, the study uses both qualitative and quantitative research methods. To achieve the new paradigm, the study in the first phase identifies the barriers the particular industry could face in transitioning towards the CSCM approach. The identified set of barriers are then evaluated using a novel fuzzy MCDM approach known as F-FUCOM. The results from F-FUCOM suggest "lack of financial resources and funding", "market challenges", and "lack of coordination and collaboration among the entire supply chain network" to be the top-most barriers having de-fuzzified weights of $0.1170,0.1048$, and 0.0928 , respectively. To counter those barriers, the study in the second stage identifies a set of enablers that would help the particular industry to effectively transition towards the new approach. Here, the TQM tool, i.e. FQFD, is used to evaluate the enablers based on the prioritized barriers achieved from the F-FUCOM approach. Based on the achieved results, "industrial symbiosis" has been considered as the most effective enabler having the crisp or de-fuzzified value of 1.00. An industrial symbiotic network would give the particular industry a competitive advantage. The waste associated with the particular industry can be used as a raw material in other industries. This as a result would financially benefit the industry as well as aid them to minimize their waste. The second most effective enabler that the industry needs to look into is the adoption of the "RL infrastructure", which received a crisp value of 0.80 . The RL infrastructure should not only focuses on the retrieval of expired medications from the market but should also focus on the retrieval of leftover medications for further donation or treatment purposes. The third most effective enabler from the HOQ is the digitalization of the entire drug supply chain network through the adoption of "block chain technology". The particular enabler received a weightage of 0.75 . This as a result would help the industry in digitizing its physical assets, ensuring better security, transparency, and visibility of 


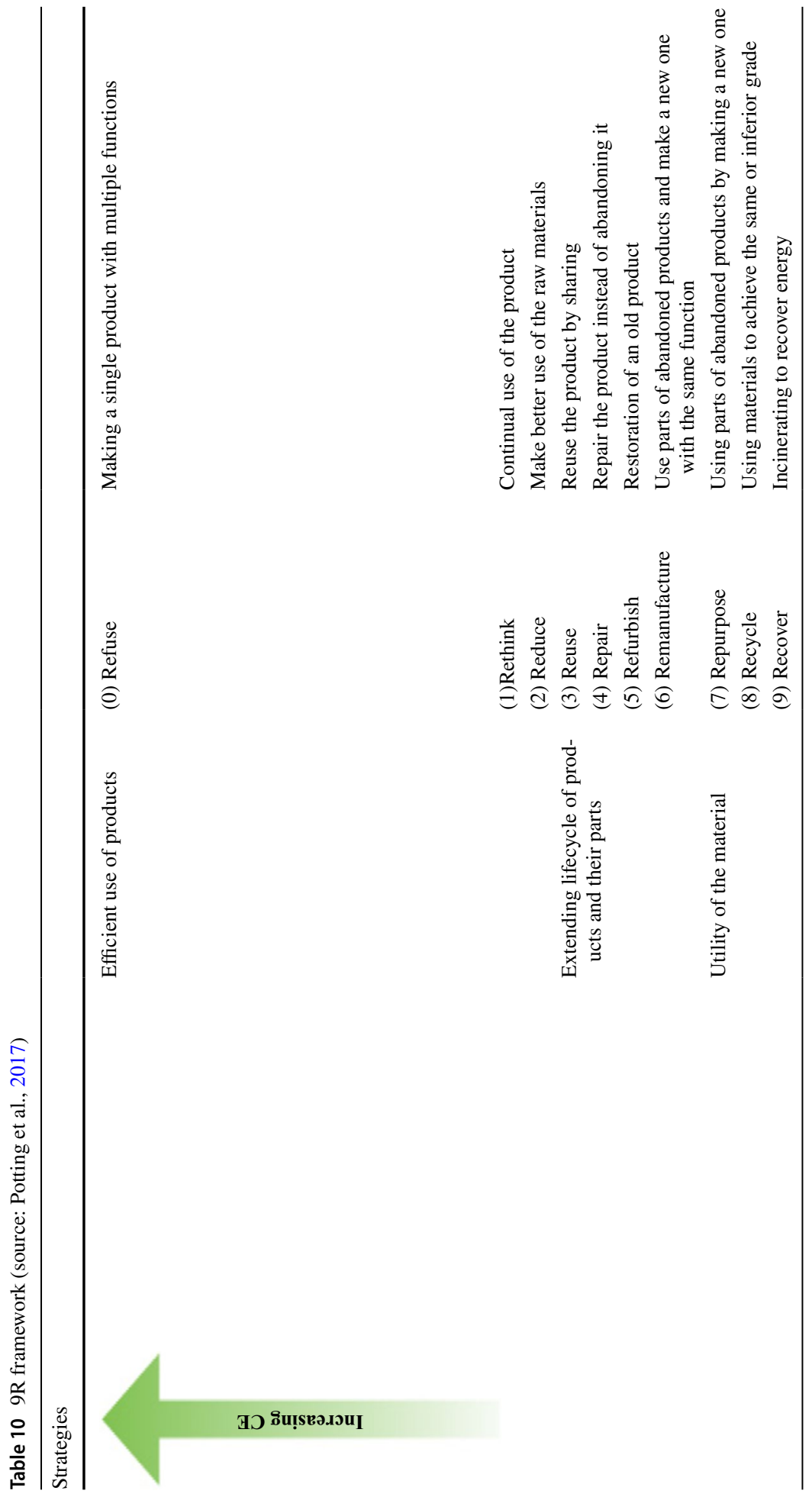


the supply chain network. It would also help the industry to control counterfeited medicines across its supply chain.

The limitations of this work lie in the probability that the secondary literature might contain other barriers and enablers that might have been missed which could affect the pharmaceutical industry in adopting the CSCM approach. However, this study adopts ten barriers and twelve enablers from the literature with the help of experts and proposes a supporting framework accordingly. Future studies should focus on other sets of barriers and enablers along with the usage and development of new approaches. Future studies can also consider performing a techno-economic analysis of the framework presented in this study.

\section{Appendix A}

Min $\chi$.

s.t.

$$
\left\{\begin{array}{l}
\left|\frac{w_{m}}{w_{m+1}}-\emptyset_{m /(m+1)}\right| \leq \chi \forall p \\
\frac{w_{m}}{w_{m+2}}-\emptyset_{m /(m+1)} \times \emptyset_{m+1 /(m+2)} \mid \leq \chi \forall p \\
\sum_{p=1}^{m} w_{p}=1, \forall p, \\
w_{p}^{u} \leq w_{p}^{v} \leq w_{p}^{x}, \\
w_{p}^{u} \geq 0, \forall p, \\
p=1,2, \ldots, n
\end{array}\right.
$$

$$
p=1,2, \ldots, n
$$

where $w_{p}=\left(w_{p}^{u}, w_{p}^{v}, w_{p}^{x}\right)$ and $\emptyset_{m /(m+1)}=\left(\emptyset_{\frac{m}{m+1}}^{u}, \emptyset_{\frac{m}{m+1}}^{v}, \emptyset_{\frac{m}{m+1}}^{x}\right)$ (Figs. 3 and 4). 
Fig. 3 Framework used in this study

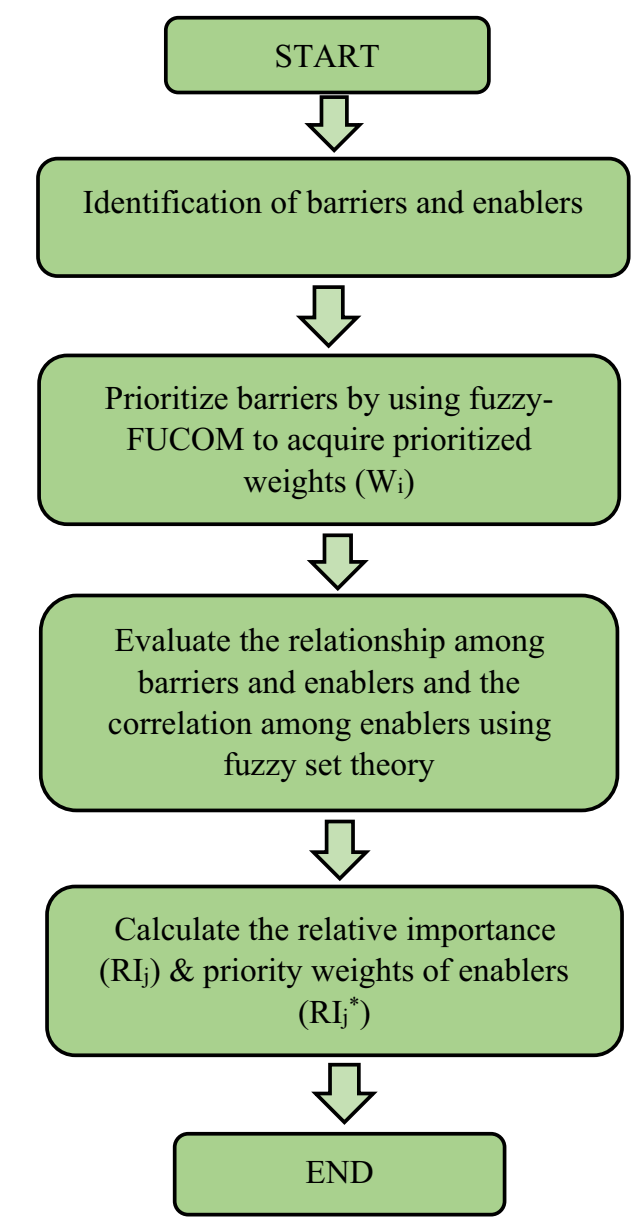




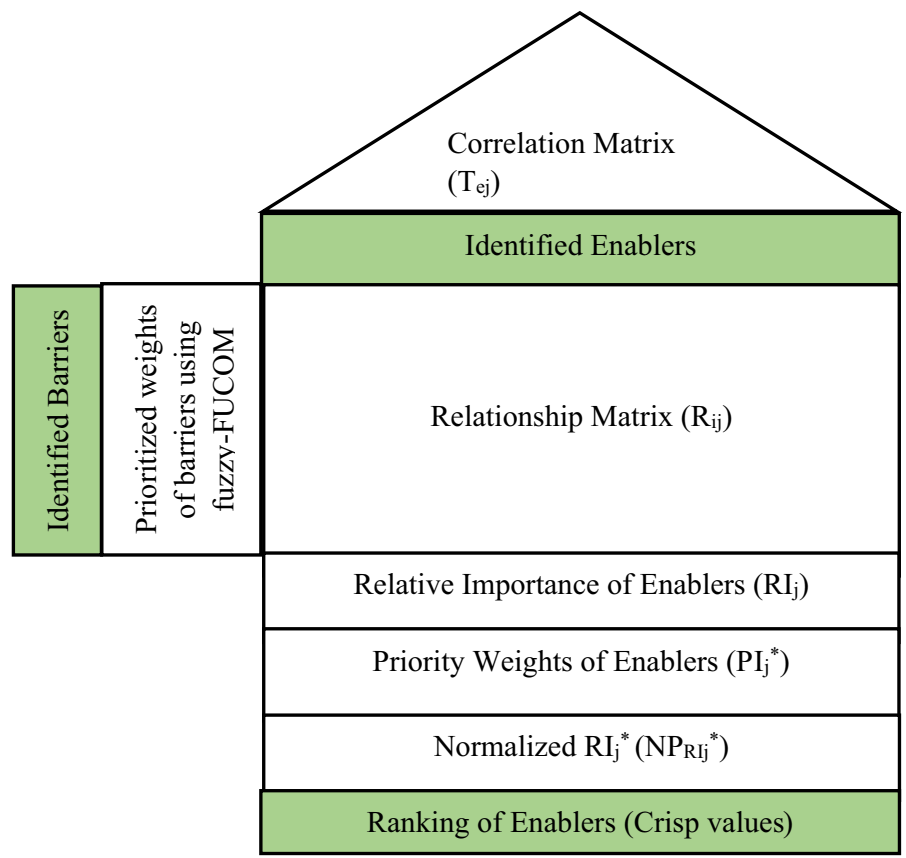

Fig. 4 Proposed fuzzy FUCOM-QFD approach (HOQ)

To achieve the highest consistency, the following conditions need to be satisfied, i.e. $\frac{w_{m}}{w_{m+1}}$ $-\emptyset_{\frac{m}{m+1}}=0$ and $\frac{w_{m}}{w_{m+2}}-\emptyset_{m /(m+1)} \times \emptyset_{m+1 /(m+2)}=0$. The model given in Eq. (14) can now be transformed into its corresponding fuzzy linear model.

Min $\chi$.

s.t.

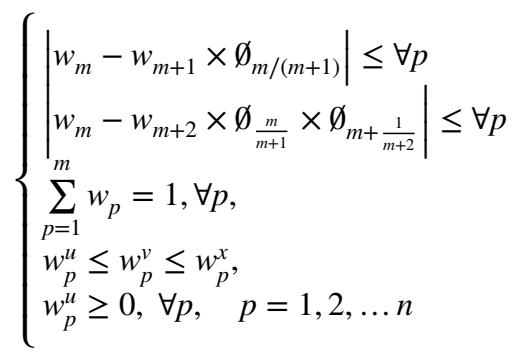

$-, p=1,2, \ldots, n$ where, $w_{p}=\left(w_{p}^{u}, w_{p}^{v}, w_{p}^{x}\right)$ and $\emptyset_{m /(m+1)}=\left(\emptyset_{\frac{m}{m+1}}^{u}, \emptyset_{\frac{m}{m+1}}^{v}, \emptyset_{\frac{m}{m+1}}^{x}\right)$.

\section{References}

Abbas, H., 2018. Barriers to reverse logistics practices in pharmaceutical supply chains: an ISM approach. International Journal of Business Excellence, 16(1). 
Abbasi, H., \& Farooquie, J. A. (2018). Framework for Reverse Logistics Practices in Pharmaceutical Supply. International Journal of Pure and Applied Mathematics, 119(16), 2343-2358.

Abreu, M. C. S., \& Ceglia, D. (2018). On the implementation of a circular economy: The role of institutional capacity-building through industrial symbiosis. Resources, Conservation and Recycling, $138(1), 99-109$.

Agyemang, M. (2019). Drivers and barriers to circular economy implementation: An explorative study in Pakistan's automobile industry. Management Decision, 57(4), 971-994.

Alshemari, A., Breen, L., Quinn, G., \& Sivarajah, U. (2020). Can We Create a Circular Pharmaceutical Supply Chain (CPSC) to Reduce Medicines Waste? Pharmacy, 8(4), 221.

Ang, K. . L. et al., (2020). Sustainability framework for pharmaceutical manufacturing (PM): A review of research landscape and implementation barriers for circular economy transition. Journal of Cleaner Production, 280(2), 124264.

Ariffin, M. \& Zakili, T. S. T. (2019). Household pharmaceutical waste disposal in Selangor, MalaysiaPolicy, Public Perception, and Current Practices. Environmental Management, 64, 509-519.

Ashton, W. (2018). Understanding the Organization of industrial ecosystems. Journal of Industrial Ecology, 12(1), 34-51.

Ayağ, Z., Samanlioglu, F. \& Büyüközkan , G. (2013). A fuzzy QFD approach to determine supply chain management strategies in the dairy industry. Journal of Intelligent Manufacturing, 24 (1), 1111-1122.

Badi, I. \& Kridish, M. (2020). Landfill site selection using a novel FUCOM-CODAS model: A case study in Libya. Scientific African, 9, e00537.

Bamakan, S. M. H., Moghaddam, S. G. \& Manshadi, S. D. (2021). Blockchain-enabled pharmaceutical cold chain: Applications, key challenges, and future trends. Journal of Cleaner Production, 302, 127021.

Batista, L., Gong, Y., Pereira, S., \& Bittar, A. (2019). Circular supply chains in emerging economies-a comparative study of packaging recovery ecosystems in China and Brazil. International Journal of Production Research, 57(23), 7248-7268.

Bevilacqua, M., Ciarapica, F., \& Giacchetta, G. (2006). A fuzzy-QFD approach to supplier selection. Journal of Purchasing and Supply Management, 12(1), 14-27.

Blagojević, A., et al. (2021). Evaluation of safety degree at railway crossings in order to achieve sustainable traffic management: A novel integrated Fuzzy MCDM model. Sustainability, 13(2), 832.

Bocek, T., Rodrigues, B. B., Strasser, T., \& Stiller, B. (2017). Blockchains everywhere-a use-case of blockchains in the pharma supply-chain (pp. 772-777). IEEE.

Bottani, E. (2009). A fuzzy QFD approach to achieve agility. International Journal of Production Economics, 119(2), 380-391.

Bottani, E., \& Rizzi, A. (2006). Strategic management of logistics service: A fuzzy QFD approach. International Journal of Production Economics, 103(2), 585-599.

Bressanelli, G., Perona, M., \& Saccani, N. (2019). Challenges in supply chain redesign for the Circular Economy: A literature review and a multiple case study. International Journal of Production Research, 57(23), 7395-7422.

Bungau, S. et al., (2018). Aspects Regarding the Pharmaceutical Waste Management in Romania. Sustainability, 10(8), 2788.

Campos, E. A. R., Paula, I. C. d., Pagani, R. N. \& Guarnieri, P. (2017). Reverse logistics for the end-oflife and end-of-use products in the pharmaceutical industry: A systematic literature review. Supply Chain Management, 22(4), 375-392.

Carraresi, L., Berg, S., \& Bröring, S. (2018). Emerging value chains within the bioeconomy: Structural changes in the case of phosphate recovery. Journal of Cleaner Production, 183, 87-101.

Chen, Y., \& Ngai, E. (2008). A fuzzy QFD program modelling approach using the method of imprecision. International Journal of Production Research, 46(24), 6823-6840.

Chien, C.-J., \& Tsai, H.-H. (2000). Using fuzzy numbers to evaluate perceived service quality. Fuzzy Sets and Systems, 116(2), 289-300.

Çil, İ, \& Evren, R. (1998). Linking of Manufacturing Strategy, Market Requirements and Manufacturing Attributes In Technology Choice: An Expert System Approach. The Engineering Economist, 43(3), 183-202.

Clauson, K. A., Breeden, E. A., Davidson, C., \& Mackey, K., T. (2018). Leveraging blockchain technology to enhance supply chain management in healthcare. Blockchain in Healthcare Today, 1(1), 1-19.

Commission, E. (2018). Impacts of circular economy. Cambridge Econometrics, Trinomics, and ICF.

Dhull, S., \& Narwal, M. (2016). Drivers and barriers in green supply chain management adaptation: A state-of-art review. Uncertain Supply Chain Management, 4(1), 61-76.

Ding, B. (2018). Pharma Industry 4.0: Literature review and research opportunities in sustainable pharmaceutical supply chains. Process Safety and Environmental Protection, 119, 115-130. 
Durmić, E., et al. (2020). Sustainable supplier selection using combined FUCOM-Rough SAW model. Reports in Mechanical Engineering, 1(1), 34-43.

Ecer, F., \& Pamucar, D. (2020). Prioritizing the weights of the evaluation criteria under fuzziness: The fuzzy full consistency method-FUCOM-F. Facta Universitatis Series Mechanical Engineering, $18(3), 419-437$.

EFPIA. (2016). EFPIA White Paper on Circular Economy. EFPIA.

EPA. (2019). Pharmaceutical Manufacturing Waste Management Trend in the 2016 TRI National Analysis. United States Environmental Protection Agency.

Farooque, M., Zhang, A., \& Liu, Y. (2019). Barriers to circular food supply chains in China. Supply Chain Management, 24(5), 677-696.

Filippis, P. D., Caprariis, B., Scarsella, M. \& Verdone, N. (2012). Energy Recovery From Unused And Expired Medicines. WIT Transactions on Ecology and the Environment, 163, 125-133.

Frigo, A. \& Lucchini, M. (2018). Working together towards circular economy: recovery and redistribution of surplus food for social purposes. Greece, 6th International Conference on Sustainable Solid Waste Management.

Geissdoerfer, M., Savaget, P., Bocken, N. M., \& Hultink, E. J. (2017). The Circular Economy-A new sustainability paradigm? Journal of Cleaner Production, 143, 757-768.

Govindan, K., \& Hasanagic, M. (2018). A systematic review on drivers, barriers, and practices towards circular economy: A supply chain perspective. International Journal of Production Research, 56(1-2), $278-311$.

Haq, I. \& Esuka, O. M. (2018). Blockchain Technology in Pharmaceutical Industry to Prevent Counterfeit Drugs. International Journal of Computer Applications, 180 (5).

Hartley, K., Santen, R. \& Kirchherr, J. (2020). Policies for transitioning towards a circular economy: Expectations from the European Union (EU). Resources, Conservation and Recycling, 155, 104634.

Hauser, J.R. (1993). How Puriten-benett used the house of quality. MIT Sloan Management Review, 34(3).

Hsieh, D. S., et al. (2017). A process for active pharmaceutical ingredient recovery from tablets using Green Engineering Technology. Organic Process Research \& Development, 29(9), 1272-1285.

Hui, T. K. L., et al. (2020). Enhancing pharmaceutical packaging through a technology ecosystem to facilitate the reuse of medicines and reduce medicinal waste. Pharmacy, 8(2), 58.

Hussain, M. \& Malik, M., (2020). Organizational enablers for circular economy in the context of sustainable supply chain management. Journal of Cleaner Production, 256, 120375.

Jia, F., Yin, S., Chen, L. \& Chen, X. (2020). The circular economy in the textile and apparel industry: A systematic literature review. Journal of Cleaner Production, 259, 120728.

Kazancoglu, Y., \& Aksoy, M. (2011). A fuzzy logic-based quality function deployment for selection of E-Learning provider. Turkish Online Journal of Educational Technology, 10(4), 39-45.

Khan, A., \& Subzwari, M. (2009). Reverse Logistics in Pakistan's Pharmaceutical Sector. South Asian Journal of Management Sciences, 3(1), 27-36.

Khan, F., Ali, Y., \& Khan, A. U. (2020a). Sustainable hybrid electric vehicle selection in the context of a developing country. Air Quality, Atmosphere \& Health, 13, 489-499.

Khan, F., Ali, Y., \& Khan, A. U. (2020b). Sustainable hybrid electric vehicle selection in the context of a developing country. Air Quality, Atmosphere \& Health Volume, 113, 489-499.

Khan, F., Ali , Y. \& Pamucar, D., 2021. A new fuzzy FUCOM-QFD approach for evaluating strategies to enhance the resilience of the healthcare sector to combat the COVID-19 pandemic. Kybernetes, ahead-of-print(ahead-of-print).

Khandelwal, C. \& Barua, M. K., 2020. Prioritizing Circular Supply Chain Management Barriers Using Fuzzy AHP: Case of the Indian Plastic Industry. Global Business Review.

Kirchherr, J., Reike, D., \& Hekkert, M. (2017). Conceptualizing the circular economy: An analysis of 114 definitions. Resources, Conservation \& Recycling, 127, 221-232.

Kongar, E., Haznedaroglu, E., Abdelghany, O., \& Bahtiyar, M. O. (2015). A novel IT infrastructure for reverse logistics operations. Information Technology and Management, 16(1), 51-65.

Kumar, A., et al. (2019). When risks need attention: Adoption of green supply chain initiatives in the pharmaceutical industry. International Journal of Production Research, 57(11), 3554-3576.

Lahane, S., Kant, R. \& Shankar, R., 2020. Circular supply chain management: A state-of-art review and future opportunities. Journal of Cleaner Production, 258(1), p. 120859.

Leigh, M., \& HongLi, X. (2015). Industrial ecology, industrial symbiosis and supply chain environmental sustainability: A case study of a large UK distributor. Journal of Cleaner Production, 106, 632-643.

Lieder, M., \& Rashid, A. (2016). Towards circular economy implementation: A comprehensive review in context of manufacturing industry. Journal of Cleaner Production, 115, 36-51.

Liu, H.-T. (2009). The extension of fuzzy QFD: From product planning to part deployment. Expert Systems with Applications, 36(8), 11131-11144. 
Mangla, S. K., et al. (2018). Barriers to effective circular supply chain management in a developing country context. Production Planning \& Control, 29(6), 551-569.

Maranesi, C., \& Giovanni, P. D. (2020). Modern circular economy: Corporate strategy, supply chain, and industrial symbiosis. Sustainability, 12(22), 9383.

Mathews, J. A., Tang, Y., \& Tan, H. (2011). China's move to a Circular Economy as a development strategy. Asian Business \& Management, 10(1), 463-484.

Meherishi, L., Narayana, S. . A. \& Ranjani, K. (2019). Sustainable packaging for supply chain management in the circular economy: A review. Journal of Cleaner Production, 237, 117582.

Moktadir, . A. et al. (2020). Circular economy practices in the leather industry: A practical step towards sustainable development. Journal of Cleaner Production, 251 (1), 119737.

Motlagh, S.-M. H., Nami, N. \& Farshadfar, Z. (2020). Collection disruption management and channel coordination in a socially concerned closed-loop supply chain: A game theory approach. Journal of Cleaner Production, 276, 124173.

Nasir, M. H. A., et al. (2017). Comparing linear and circular supply chains: A case study from the construction industry. International Journal of Production Economics, 183(2), 443-457.

Ngan, S. L., et al. (2019). Prioritization of sustainability indicators for promoting the circular economy: The case of developing countries. Renewable and Sustainable Energy Reviews, 111(1), 314-331.

Niu, B., Dong, J. \& Liu, Y. (2021). Incentive alignment for blockchain adoption in medicine supply chains. Transportation Research Part E: Logistics and Transportation Review, 152, 102276.

Niza, S., et al. (2014). Extended producer responsibility policy in Portugal: A strategy towards improving waste management performance. Journal of Cleaner Production, 64, 277-287.

Ong, M. C., Leong, Y. T., Wan, Y. K., \& Chew, I. M. L. (2021). Multi-objective optimization of Integrated Water System by FUCOM-VIKOR Approach. Process Integration and Optimization for Sustainability, 5, 43-62.

Osorio-Gómez, J. C., Manotas-Duque, D. F., Rivera-Cadavid, L., \& Canales-Valdiviezo, I. (2018). Operational risk prioritization in supply chain with 3PL using Fuzzy-QFD. In New Perspectives on Applied Industrial Tools and Techniques (pp. 91-109). Cham: Springer.

Pamučar, D., Stević, Ž, \& Sremac, S. (2018). A new model for determining weight coefficients of criteria in MCDM models: Full Consistency Method (FUCOM). Symmetry, 10(9), 393.

Pamucar, D., Ecer, F. \& Deveci, M. (2021). Assessment of alternative fuel vehicles for sustainable road transportation of United States using integrated fuzzy FUCOM and neutrosophic fuzzy MARCOS methodology. Science of The Total Environment, 788, 147763.

Pan, Y. S. et al. (2015). Strategies on implementation of waste-to-energy (WTE) supply chain for circular economy system: a review. Journal of Cleaner Production, 108(A), 409-421.

Potting, J., Hekkert, . M., Worrell, E. \& Hanemaaijer, A. (2017). Circular Economy: Measuring Innovation in the Product Chain, Hague: PBL.

Pramanik, D., et al. (2017). Resilient supplier selection using AHP-TOPSIS-QFD under a fuzzy environment. International Journal of Management Science and Engineering Management, 12(1), 45-54.

Rajesh, G., \& Malliga, P. (2013). Supplier selection based on AHP QFD Methodology. Procedia Engineering, 64, 1283-1292.

Roberta, A., Howard, M. \& Miemczyk, J. (2018). Supply chain management and the circular economy: Towards the circular supply chain. Production Planning and Control, 29(6), 425-437.

Roghanian, E., \& Alipour, M. (2014). A fuzzy model for achieving lean attributes for competitive advantages development using AHP-QFD-PROMETHEE. Journal of Industrial Engineering International, 10,68 .

Roschangar, F., Sheldon, R. A., \& Senanayake, C. H. (2015). Overcoming barriers to green chemistry in the pharmaceutical industry-the Green Aspiration Level ${ }^{\mathrm{TM}}$ concept. Green Chemistry, 17, $752-768$.

Sara, S., Kouhizadeh, M., Sarkis, J., \& Shen, L. (2018). Blockchain technology and its relationships to sustainable supply chain management. International Journal of Production Research, 57(7), 2117-2135.

Sazvar, Z. et al. (2021). Designing a sustainable closed-loop pharmaceutical supply chain in a competitive market considering demand uncertainty, manufacturer's brand and waste management. Annals of Operations Research.

Schroeder, P., Anggraeni, K., \& Weber, U. (2019). The relevance of circular economy practices to the sustainable development goals. Journal of Industry Ecology, 23(1), 77-95.

Shahin, A., Masoomi, B. \& Shafiei, M. A. (2019). Ranking the obstacles of green supply chain management using fuzzy approaches of TOPSIS and DEMATEL with a case study in a pharmaceutical industry. International Journal of Logistics Systems and Management, 33 (3). 
Sharma, Y. K., Mangla, S. K., Patil, P. P., \& Liu, S. (2019). When challenges impede the process: For circular economy-driven sustainability practices in food supply chain. Management Decision, 57(4), 995-1017.

Simić, J. M., et al. (2020). A Novel CRITIC-Fuzzy FUCOM-DEA-Fuzzy MARCOS Model for safety evaluation of road sections based on geometric parameters of road. Symmetry, 12(12), 2006.

Singh, R. K., Kumar, R., \& Kumar, P. (2016). Strategic issues in pharmaceutical supply chains: A review. International Journal of Pharmaceutical and Healthcare Marketing, 10(3), 234-257.

Singh, M. P., Chakraborty, A., \& Roy, M. (2018). Developing an extended theory of planned behavior model to explore circular economy readiness in manufacturing MSMEs, India. Resources, Conservation and Recycling, 135, 313-322.

Smale, E. M. et al. (2021). Waste-minimising measures to achieve sustainable supply and use of medication. Sustainable Chemistry and Pharmacy, 20, 100400.

Sohn, S. Y., \& Choi, I. S. (2001). Fuzzy QFD for supply chain management with reliability consideration. Reliability Engineering \& System Safety, 72(3), 327-334.

Statista, 2020. Statista. [Online]. Available at: https://www.statista.com/statistics/280572/medicine-spend ing-worldwide/. [Accessed 30 November 2020].

$\mathrm{Su}, \mathrm{G}$. et al. (2021). Valorisation of medical waste through pyrolysis for a cleaner environment: Progress and challenges. Environmental Pollution, 279, 116934.

Sylim, P., Liu, F., Marcelo, A. \& Fontelo, P. (2018). Blockchain technology for detecting falsified and substandard drugs in distribution: Pharmaceutical supply chain intervention. Pharmaceutical Supply Chain Intervention, 7(9).

Tang, C., Xu, D., \& Chen, N. (2021). Sustainability prioritization of sewage sludge to energy scenarios with hybrid-data consideration: A fuzzy decision-making framework based on full consistency method and fusion ranking model. Environmental Science and Pollution Research, 28, 5548-5565.

The World Bank. (2019). Solid Waste Management. The world bank.

Uthayakumar, R., \& Priyan, S. (2013). Pharmaceutical supply chain and inventory management strategies: Optimization for a pharmaceutical company and a hospital. Operations Research for Health Care, 2(3), 52-64.

Veleva, V. R., \& CueJr, B. W. (2019). The role of drivers, barriers, and opportunities of green chemistry adoption in the major world markets. Current Opinion in Green and Sustainable Chemistry, 19(1), 30-36.

Veleva, V. R., Cue, B. W., Jr., \& Todorova, S. (2018). Benchmarking Green Chemistry Adoption by the Global Pharmaceutical Supply Chain. ACS Sustainable Chemistry \& Engineering, 6(1), 2-14.

Viegas, C. V., Bond, A., Vaz, C. R. \& Bertoloe, R. J. (2019). Reverse flows within the pharmaceutical supply chain: A classificatory review from the perspective of end-of-use and end-of-life medicines. Journal of Cleaner Production, 238, 17719.

Vinod, S., \& Chinta, S. K. (2011). Application of fuzzy QFD for enabling leanness in a manufacturing organisation. International Journal of Production Research, 49(6), 1627-1644.

Wen, Z., \& Meng, X. (2015). Quantitative assessment of industrial symbiosis for the promotion of circular economy: A case study of the printed circuit boards industry in China's Suzhou New District. Journal of Cleaner Production, 90, 211-219.

Weraikat, D., Zanjani, M. K., \& Lehoux, N. (2016a). Coordinating a green reverse supply chain in pharmaceutical sector by negotiation. Computers \& Industrial Engineering, 93, 67-77.

Weraikat, D., Zanjani, M. K., \& Lehoux, N. (2016b). Two-echelon pharmaceutical reverse supply chain coordination with customers incentives. International Journal of Production Economics, 176, 41-52.

WHO. (1999). Guidelines for Safe Disposal of Unwanted Pharmaceuticals in and After Emergencies. WHO.

WHO. (2018). World Health Organaization. [Online]. Available at: https://www.who.int/news-room/factsheets/detail/health-care-waste. [Accessed 29 November 2020].

Zadeh, L. (1965). Fuzzy sets. Information and Control, 8(3), 338-353.

Zaid, A. A., Jaaron, A. A., \& Bon, A. T. (2018). The impact of green human resource management and green supply chain management practices on sustainable performance: An empirical study. Journal of Cleaner Production, 204, 965-979.

Zarei, M., Fakhrzad, M., \& Paghaleh, M. J. (2011). Food supply chain leanness using a developed QFD model. Journal of Food Engineering, 102(1), 25-33.

Zimmermann, H.-J. (1991). Fuzzy Set Theory—and Its Applications. fourth (edition). Academic publishers.

Publisher's Note Springer Nature remains neutral with regard to jurisdictional claims in published maps and institutional affiliations. 